\title{
Formation of Creativity Skills in Engineering Education Through the Disciplines of the Humanitarian and Legal Cycle
}

\author{
Olga V. Sudakova ${ }^{*}$ [ORCID 0000-0002-9070-1470]
}

\author{
${ }^{1}$ Samara State Transport University, Samara, Russia \\ o.sudakova@samgups.ru
}

\begin{abstract}
The article substantiates the role of creativity in the formation of meta-competencies of students, future engineers. The experience of the departments of transport law and personnel management of the Samara State Transport University (Samara, Russia) in teaching disciplines of socio-economic and humanitarian cycles is analyzed. Examples of successful pedagogical practice of using various forms of interaction between teachers and students in the learning process are given: discussion, business role-playing game, essay. The position on the relationship between the formation of students' creative abilities in the process of conducting such classes and their subsequent transformation in engineering education is argued. A parallel is drawn between academic education in higher education and the creative forms of work of students and teachers. The level of students' creative potential is made dependent on the professional level of the teaching staff; at the same time, the most important role of the latter is emphasized. The article discusses in detail the universal competencies formed in the process of training in engineering specialties, and their relationship with the disciplines of the socioeconomic and humanitarian cycle.
\end{abstract}

Keywords: creativity, meta competence, engineering education, creative process, forms of conducting classes, pedagogical skills, disciplines of the humanitarian cycle in engineering education

\section{INTRODUCTION}

In the era of widespread informatization of society, novelty is a very illusory concept, transformation of what is already known is also problematic. The very process of creativity is the process of creating something new, the result of transforming existing experience through original methods and non-standard ways.

The categories of creativity are highly subjective. However, even Plato said that "Everything that causes the transition from nonexistence to being, creativity, and, therefore, the creation of any works of art and craft can be called creativity, and all their authors creators" [1]. Definitely, the creative process is aimed at creating a material product, but the birth of an idea is the beginning of this creative process.

V.I. Zagvyazinsky in his work "Pedagogicheskoe tvorchestvo uchitelya" ["Pedagogical creativity of a teacher"] writes: "They argue about what is the criterion of creative activity - a process or a product, about whether the features inherent in creativity novelty and transformation - should act as objective indicators of development, or they can be subjective, that is, the course of the search and its result will be new only for the cognizing subject, but not for society as a whole. In the pedagogical process, these positions are not mutually exclusive. In any case, the psychological nature of the creative act, in principle, does not change from whether the new is created objectively or only subjectively" [2].

The author agrees with I.A. Beskova, who claims that "creativity is a phenomenon, basically correlated with spontaneity, freedom, openness, integrity, connectedness of everything with everything and a variety of mutual influences, when a seemingly insignificant factor, a slight impulse, an accidental coincidence provoke previously not existing forms of disclosure and previously unpredictable ways of the evolution of events" [3]. 
The thesis that engineering creativity is aimed primarily at the result, at the product of this process, and should be characterized by novelty in an objective sense, is not questioned. For humanitarian creativity, the primary is thought, the subjective novelty of the author's position, their assessments and feelings. A teacher of humanities and social disciplines at an engineering university acts as an intermediary between subjective and objective creative product.

It should be stated with confidence that the creative process in the framework of obtaining an engineering education cannot be limited only to the disciplines of specialization. Most scientists today agree that it is an integrated approach to the formation of a graduate of a higher school - a specialist in the engineering field that is an effective solution to scientific problems and a path to the development of new technologies [4].

In their study, the authors set a goal: to identify the patterns of the formation of creative abilities among students of engineering specialties through training in the disciplines of the humanitarian and socio-economic cycles.

The objectives to be solved in the course of the research:

- to analyze the structure and role of the competence-based approach in the educational process of universities that train specialists in the engineering field (on the example of the Samara State Transport University - hereinafter SamGUPS);

- to study and summarize the experience available at the university in teaching methods of humanitarian and socio-economic disciplines (for example, the departments of "Transport Law" and "Personnel Management");

- to establish a connection between the development of creative abilities among students of engineering specialties and competencies that are formed during training at the classes of humanitarian and socioeconomic disciplines.

\section{MATERIALS AND METHODS}

The fundamental ideas of the research are theses about the creative process as an activity aimed at creating new knowledge, a product; use of hypotheses, intuition, insight, revelations in the process of activity; the impossibility of using logical methods when deriving the result of creativity.

The defining research methods are system analysis, student polls and an experimental method for studying the problems of forming the creative abilities of SamGUPS students. The systematic method of scientific knowledge allows for revealing the integrity and complex nature of the problems of the creative process, including identifying the interrelationships of individual stages of creativity and their influence on the process itself and its product.

At the same time, in the study of creativity, it is also necessary to use an experimental method that allows one to discover repetitive, stable, necessary connections between phenomena, i.e. study the patterns, characteristic features for the creative process. Also, in the process of research, we used surveys of students of engineering specialties of 3-5 courses of SamGUPS in the areas of training 23.05.03 - Rolling stock of railways, 23.05.04 Operation of railways, 23.05.05 - Railway traffic control systems.

\section{RESULTS}

According to L.P. Khalyapina (Zaitseva): "Modern conditions, the situation of a technological explosion, globalization and the increasing mobility of qualification characteristics put to the fore not professional skills, but basic and social competences: the ability of an individual to independently build their life path in a contradictory, constantly changing world" [5].

According to the Federal State Educational Standard $3++$, approved by orders of the Ministry of Education and Science of the Russian Federation No. 215, 216, 217 of 2018 "On the approval of the federal state educational standard of higher education", respectively, in the specialties 23.05.03, 23.05.04, 23.05.05 [6], according to the results of mastering the program of the specialty in engineering specialties of the direction of 23.05.00 the universal competencies are the following abilities:

- to carry out a critical analysis of problem situations on the basis of a systematic approach, to develop an action strategy;

- to manage a project at all stages of its life cycle;

- to organize and manage the work of a team, developing a team strategy to achieve the set goal; 
- to apply modern communication technologies, including in a foreign language(s), for academic and professional interaction;

- to analyze and take into account the diversity of cultures in the process of intercultural interaction;

- to determine and implement the priorities of one's own activity and ways to improve it on the basis of self-esteem and education throughout life, etc.

Carrying out a lexical and linguistic analysis of these competencies, one cannot but admit that the formation of this kind of knowledge, skills and abilities is impossible without a deep and comprehensive study of social sciences and humanities.

Critical analysis, a systematic approach, problem situations, an action strategy are nothing more than the result of mastering the techniques and methods of logical thinking, analysis and synthesis, predicting situations, the formation of a high level of imagination and creativity. Setting a non-standard problem and choosing the optimal way to solve it is a mutual process of co-creation between a teacher and a student.

And in this context, one cannot but take advantage of the scientific achievements in this area of such areas of knowledge as psychology, pedagogy, sociology, political science, etc. The formation of the competence of foresight, forecasting the results, products and consequences of one's professional activity is an important skill. Legal or social consequences of decision-making, psychological results of management structures, socio-economic changes - these skills are formed in future engineers in the course of studying the disciplines "Jurisprudence", "Political Science", "Sociology", "Personnel Management".

V.P. Ryzhov writes: "Designing is one of the most demanded types of creative activity now. Almost all spheres of human life are being designed: social, organizational, technical, educational, etc. But any design is, first of all, an information process, a process of generating new information" [7].

Many scientists are now talking about the humanization of engineering education. And about design, as a narrow professional activity, they propose to refuse in favor of the inclusion of technical knowledge in the general cultural context [8].

The authors of this study agree with this. The synthesis of the humanities and technical sciences, the search for common topics of discussion and development of projects ultimately leads to the formation and expansion of non-standard knowledge, the manifestation of creative abilities. The ability to work and create at the intersection of scientific disciplines is the fundamental and most important requirement of the time.

Teamwork, the ability to create and manage it is the most demanded ability on the labor market. With the existence in the world of a huge number of corporations, small and large, Russian, foreign or joint, it requires a future graduate of an engineering university to be able to get involved in the work of this corporation from the first day of their work, to adopt a corporate spirit, to become a full member of the team, and sometimes to lead it. In this case, the presence of special personal qualities, leadership needs, the ability to make creative decisions in managing a group, team are an integral part of a creative person.

A number of scientists and practitioners directly point to the creative component in the characterization of an employee. N.L. Sineva, E.V. Yashkova, T.V. Petrov write: "At present, the creativity of the company's personnel is considered as a distinctive competitive advantage. Thus, the purposeful and laborious work of personnel departments, associated with the continuous development of personnel, their motivation and incentives, becomes a self-sufficient business. The struggle of modern organizations for talented employees has given rise to a new direction in business and management - talent management [9].

Modern communication technologies, being an integral part of the life of a modern person, due to their high socialization, involvement in the process of communication with humanity via the Internet, determine their status in society, make it possible to convey the necessary information in the right way to the respondents they needs. Not only spoken language is a means of communication and exchange of information. The phenomenon of colloquial speech has been studied in detail by I.T. Veprevoy, I.N. Shalina and T.V. Matveeva [10]. For example, V.I. Andreev classifies the group of communicative abilities as undoubtedly creative [11].

"Now, when the mixing of peoples, languages, cultures has reached an unprecedented scale ... the problem of fostering tolerance for other cultures, awakening interest and respect for them has become more acute than ever" [12]. The space for the realization by the subjects of interpersonal, 
intergroup, interethnic, interethnic interaction forms a communicative field, the formation and development of which is determined by the communicative culture and communicative competence of the individual [13].

The talent in mastering the language, both native and foreign, a creative approach to defining the style of communication, the forms of expressing one's thoughts, the creativity of this expression is a necessary component of a modern engineer.

Creativity and culture are not identical concepts, but interpenetrating ones. Value orientations and the system of personal meanings constitute the valuesemantic sphere of the individual. According to I.G. Andrushchenko: "Value concepts are born as a result of the awareness of value, and on their basis value orientations arise, which, in turn, are systems of personal meanings. The value orientations of the indicators of a person's spiritual activity at the personal and collective level, which have a positive assessment, can manifest themselves in knowledge, motives, interests, ideals, ideas, as well as in attitudes and stereotypes" [14].

Education is a mechanism for the transmission of cultural values, norms, ideals. It influences not only the formation of legal consciousness, but also its ability to successfully participate in intercultural dialogue. Understanding and comprehending the culture of other peoples, thus, being a form of reproduction of the national and cultural world, turns out to be a means of developing the creative principle of any person.

\section{DISCUSSION}

Summarizing the experience of the teaching staff of the departments of transport law and personnel management of SamGUPS, it should be emphasized that a creative approach to the organization of classes on the part of teachers gives the same creative response from students. Within the framework of practical classes in the disciplines of the social and humanitarian cycle, business games, discussions and writing essays are often used.

Business role-playing games. Business roleplaying games are a very effective form of education, during which skills of socially significant and socially useful behavior are formed and consolidated in the creative process. So in the classroom on the discipline "Jurisprudence" students can be participants in the legislative process within the framework of the topic "Political ideologies", showing knowledge and ability to express their opinion based on its ideological coloring. Students are encouraged to discuss different bills on the same political platform.

Thus, the understanding of the essence of political ideologies, political parties is consolidated, the skills of political dispute, argumentation, the ability to listen to the opponent are acquired. Or, to compare democratic and authoritarian political regimes, students are encouraged to create a project following the decision-making procedure in accordance with the rules of the game of these regimes (Figure 1, Figure 2).

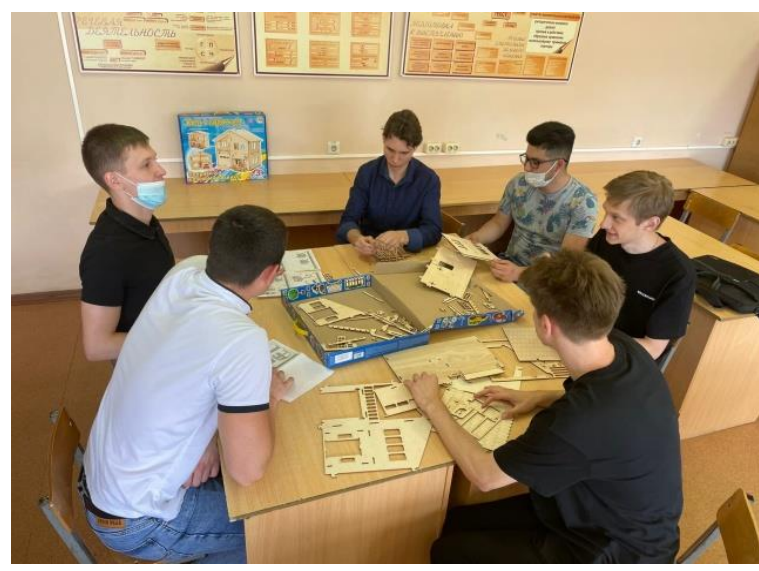

Figure 1. The process of building a house during the "Democracy and Authoritarianism" business game Source: Author's photo

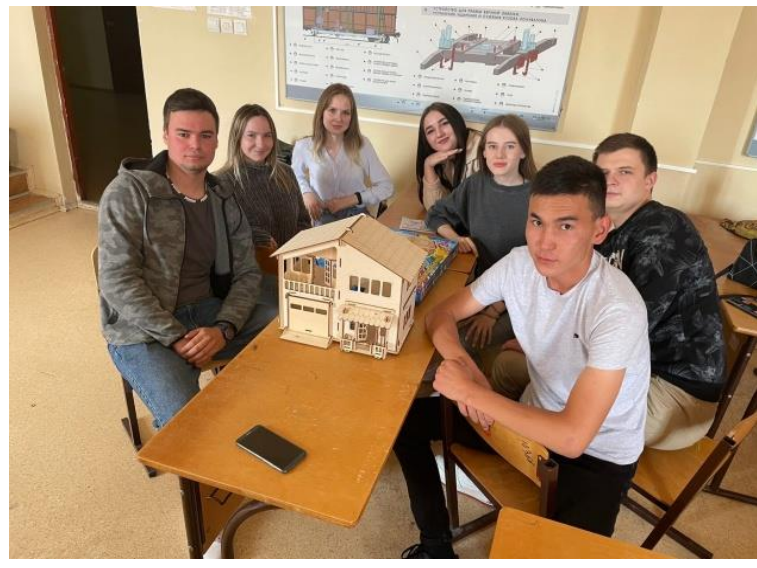

Figure 2. The result of the business game: teamwork, material outcome Source: Author's photo

Studying the topic "Political Forecasting" within the framework of the discipline "Political Science", students are encouraged to operate with statistical data published on the Internet to draw up short-term and long-term prospects for the development of social processes in Russia and the world. In the course of the "Image of a Leader" business game, 
students hone their existing skills in creating presentations, video content, photoshop to promote the "candidate" in the election campaign. When choosing such a learning technology as a business game, it is the activity-based approach and game situation that helps to free consciousness, turn to intuition and creativity, which undoubtedly gives rise to a state of creativity. Students "play" actively and with enthusiasm. At the same time, they consciously gain experience of the corresponding behavior.

Discussion. When studying legal and sociopolitical sciences, there is always room for controversy. Conducting a discussion productively, being able to reasonably defend one's point of view, operate with knowledge, figures, opinions of scientists is an excellent skill that can be useful in the professional activities of future engineers. Worthy of discussion may be the speeches of wellknown lawyers or political scientists on the Internet, whose arguments seem unconvincing, or whose conclusions on certain issues are unfounded. When proposing such topics for discussion, students should be drawn to sources that contain directly opposite judgments. Students actively engage in polemics with each other, cite the opinions of other scientists as arguments. At the same time, the ability to reasonably and reasonably express one's opinion, to argue with opponents, to work in a team of likeminded people, if there are any in a specific discussion, develops.

Essay. Writing an essay is definitely a creative task. This form is used to work with students in the disciplines of jurisprudence and political science. Reasoning on problematic topics of modern social processes generates a high emotional response. Future engineers are concerned not only and not so much with their future in the profession as with pressing social problems. Their proactive stance is manifested in the desire to take an interest in social life, analyze it, and make forecasts. Studying historical legal and political science sources, students are invited to analyze them from the point of view of the present. In this case, the mechanisms of imagination and design are actively involved, which, undoubtedly, is a manifestation of creativity. Developed written speech, the ability to convey their point of view in a concise form, the ability to formulate a hypothesis and substantiate it with formal and informal evidence, to deduce a disposition. This is the process of creating a new, still unexplored, but already having the right to exist. Each opinion is valuable in itself, because it expresses the individuality that is so necessary in the creative process.

Thus, in the educational process of the groups of students studied by the authors of the study, formallogical knowledge and methods of teaching fade into the background, making it possible for an organic combination of intuition and discourse. Today this phenomenon is undeniably more productive than academic processes. If educational activity on the part of the teacher is presented as creativity, as a harmonious combination of seemingly incongruous methods of intuitive knowledge and scientific theories, creative assumptions and logical conclusions, pragmatic calculation and creative experiment, then the process aimed at the development of creative, imaginative and intuitive thinking the learners will be more fruitful. According to the authors, both passive forms of perception and active mastery of the art of creativity are needed.

\section{CONCLUSION}

According to E.V. Mikhalkina, "Academic institutes participate in the generation of new knowledge, the development of fundamental science, the development and attraction of new educational technologies and methods" [15]. Therefore, special requirements are imposed on the teaching staff for the formation of not only professional skills and abilities among students, but building the trajectory of development of each individual, taking into account their creative abilities and capabilities.

If one imagines a school graduate on the one hand and a specialist-engineer who will be in demand in the future on the labor market, then the most effective link between these types of human life is a university teacher.

The professional reputation of a teacher today is the development of a complex of abilities. In the first place are skills and abilities in the use of computer technology, creative thinking and creativity in the organization of training sessions, general and professional erudition, the use of advanced industry knowledge and high-quality educational products in the educational process.

The standard stock of pedagogical techniques and tools, which has been established in higher education for many years, is now not relevant. Every day in the IT world there are events of a regional, national or global scale. It is the duty of the teacher to follow the news in the technical field, to be at the 
peak of advanced educational technologies. Joint discussion of significant world events: new products from Apple or Google, presentation of the Milner or Zuckerberg awards, news from the IT capital of the world. This is a rule of personal example, an enthusiastic, interested teacher is always surrounded by the same creative students.

According to R.V. Aginey, "The effectiveness of a university depends on ... a high degree of internal integration of personnel and "product consumers", ... and a high motivating value of the content of the main activity, so that the development of moral motivation largely intersects with the development of personnel competence" [16].

The education system is not a closed system and is a reflection of the mega-system of society. All social processes are also educational. Selfdevelopment, as a sign of an operating system, is reflected in education as the ability to create within oneself productive mechanisms of self-renewal, informational and creative progress, "explosion", an insight.

It is already obvious that the narrowness of standard academic criteria does not allow the creative potential of students to be realized. The forms of classes that were practiced ten years ago are already outdated and cannot meet the rapidly changing educational systems and demands of society. The pandemic has shown this most clearly.

Thus, in the course of mastering the disciplines of the socio-economic and humanitarian block, students of engineering specialties most vividly and effectively form the skills of creative thinking, imagination, project consciousness, and creative behavior. These skills are later honed in classes in technical disciplines, in the course of research and development activities.

\section{REFERENCES}

[1] "Plato Feast" [Platon Pir], Collected Works in 4 volumes, vol. 2, M.: Mysl, 1993, 115 p. (In Russ.).

[2] V.I. Zagvyazinskij, "Teacher's pedagogical creativity" [Pedagogicheskoe tvorchestvo uchitelya], M.: Pedagogika, 1987, 32 p. (In Russ.).

[3] I.A. Beskova, "Substantiation of a non-dual approach to the analysis of insightful comprehension" [Obosnovanie nedualnogo podhoda $\mathrm{k}$ analizu insajtnogo postizheniya], Philosophy of Creativity Yearbook, In Ed. by
N.M. Smirnova, I.A. Beskova, A.S. Maidanov, A.A. Gorelov, Yu.S. Morkina, E.I. Yaroslavtseva, M.: IInteLL, 2018, 422 p. (In Russ.).

[4] V.V. Rubtsov, V.A. Lectorsky, B.D. Elkonin, A.G. Asmolov, V.T. Kudryavcev, I.D. Frumin, N.M. Kovaleva, "From joint activity to the construction of new social communities: Jointness. creativity. education. school", Roundtable of the methodological seminar supervised by V.V. Rubtsov and B.D. Elkonin, Cultural-Historical Psychology, 2018, vol. 14(3), pp. 5-30. (In Russ.). DOI: 10.17759/chp.2018140302

[5] L.P. Khalyapina, "Main trends and directions in teaching foreign languages in the situation of polycultural world", Topical Issues of Philology and Methods of Foreign Languages Teaching, Novosibirsk, 2017, vol. 11, pp. 262-266. (In Russ.).

[6] Portal of Federal State Educational Standards for Higher Education [Portal Federalnyh gosudarstvennyh obrazovatel'nyh standartov vysshego obrazovaniya], 2021. (In Russ.). Retrieved from http://fgosvo.ru/fgosvo/153/150/26/70

[7] V.P. Ryzhov, "Engineering creativity and problems of modern education" [Inzhenernoe tvorchestvo i problemy sovremennogo obrazovaniya], Open Education, 2005, vol. 5, pp. 79-84. (In Russ.).

[8] O.V. Krezhevskikh, "Designing a professional biography as a predictor of continuous professional self-determination of a teacher", Perspectives of Science and Education, 2020, vol. 48(6), pp. 430-445. (In Russ.). DOI: 10.32744/PSE.2020.6.33

[9] N.L. Sineva, E.V. Yashkova, T.V. Perova, "Control over the system of creative management (management of employees' creativity) as a factor of competitive advantage of innovative organization", Naukovedenie, 2014, vol. 5(24), p. 115. (In Russ.).

[10]I. Vepreva, I. Shalina, T. Matveeva, "Russian colloquial speech: Aspects of research and relevant issues", Quaestio Rossica, 2019, vol. 7(3), pp. 919-936. DOI: 10.15826/qr.2019.3.415

[11] V.I. Andreev, "Dialectics of education and selfeducation of a creative person" [Dialektika vospitaniya i samovospitaniya tvorcheskoj 
lichnosti], Kazan: Publisher House of the KGU, 1988, 240 p. (In Russ.).

[12] N.A. Kozlovtseva, N.N. Tolstova, "Formation of the Image of the Russian World as an Aspect of Sociocultural Adaptation of Foreigners in the Process of Teaching the Russian Language", Bakhtiniana, 2019, vol. 14(1), pp. 82-113. DOI: $10.1590 / 2176-457338362$

[13] "Fundamentals of personal and communicative culture: culture and personality" [Osnovy lichnostnoj i kommunikativnoj kultury: kultura i lichnost'], textbook, In Ed. by S.V. Kushchenko, Novosibirsk: Publisher House of the NGTU, 2018, 62 p. (In Russ.).

[14]I.G. Andrushchenko, "The development of the value-semantic sphere of students in the process of studying the disciplines of the humanitarian cycle" [Razvitie tsennostno-smyslovoj sfery studentov $\mathrm{V}$ protsesse izucheniya distsiplin gumanitarnogo tsikla], National cultures in intercultural communication: Collection of articles. Scientific. Art, Part 1, Socio-historical aspects of intercultural interaction, In Ed. by E.A. Usovskaya, Minsk: Kolorgrad. 2016, pp. 8-12. (In Russ.).

[15]E.V. Mikhalkina, L.S. Skachkova, "Why do not PhD students choose job in universities?", Terra Economicus, 2018, vol. 16(4), pp. 116-129. DOI: 10.23683/2073-6606-2018-16-4-116-129

[16]R.V. Aginey, O.I. Belyaeva, "Big challenges" and regional technical university: Values and actions", Higher Education in Russia, 2020, vol. 29(2), pp. 105-114. (In Russ.). DOI: 10.31992/0869-3617-2020-29-2-105-114 